\title{
Measuring cognitive emotion regulation in South Africa using the Cognitive Emotion Regulation Questionnaire-short form
}

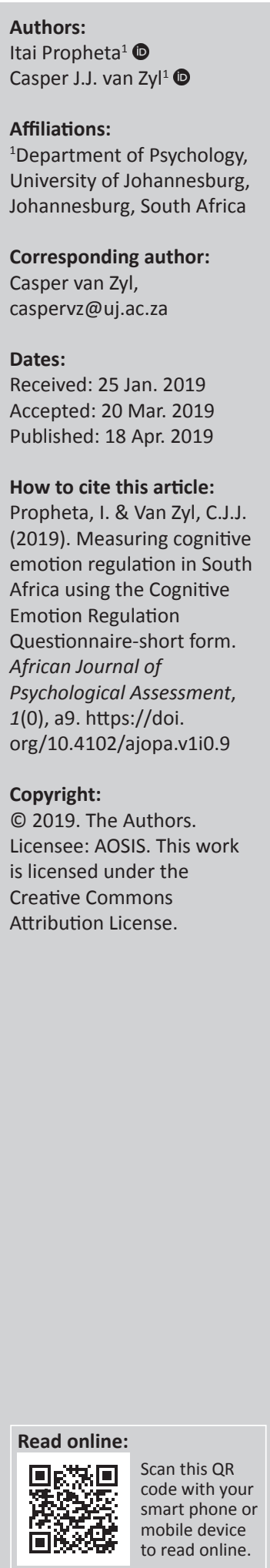

Cognitive emotion regulation plays an important role in how people manage stressful life events. Some strategies are adaptive, while others are maladaptive and linked to several forms of psychopathology. The Cognitive Emotion Regulation Questionnaire (CERQ)-short form measures an individual's proclivity to use different strategies in response to longer term stressors. The CERQ-short was developed in the Netherlands, and although it has been standardised in several countries, it is yet to be validated for use in South Africa. The aim of this study was to evaluate the psychometric properties of the CERQ-short within the South African context. The study was conducted at a large urban university in the Gauteng province of South Africa. The above was considered on the basis of a reliability analysis and an investigation into the confirmatory factor structure of the CERQ-short using data from a group of urban South African university students $(n=1904)$. With some exceptions, results indicated acceptable reliability for the scales ranging between 0.58 and 0.82 . Confirmatory factor analysis found reasonable support for a basic nine-factor model. The measurement properties of the CERQ-short were found to be weaker in South Africa compared to that reported in its country of origin. But it was nonetheless found to hold promise for use in our multicultural and multilingual context. In particular, it may be useful for research studies where brevity is called for.

Keywords: CERQ-short; cognitive emotion regulation; psychometric properties; reliability; validity.

\section{Introduction}

The influence of emotions on our daily lives can hardly be overstated. They directs attention in our environment, facilitate decision-making, shape behavioural responses and impact memory formation to highlight a few functions (Gross, 2014). Such examples show that everyday functioning requires all individuals to engage in some minimum level of emotion regulation all the time (Davidson, 1998). While wonderfully useful for adaptive functioning in general, emotions can also be the cause of substantial harm.

Indeed, the inability to regulate emotions can produce serious disruptions to adaptive psychological functioning (Koole, 2009). Failure to regulate emotions effectively has been implicated in the emergence and maintenance of several forms of psychopathology, including depression and anxiety (Bebko, Ochsner, Franconeri, \& Chiao, 2014), schizophrenia (Gross \& Jazaieri, 2014), social anxiety (Klemanski, Curtiss, McLaughlin, \& Nolen-Hoeksema, 2017), eating disorders (Mallorqui-Bague et al., 2017), personality disorders (Fitzpatrick, Khoury, \& Kuo, 2018) and mood disorders (Gruber, Hay, \& Gross, 2014; Joormann \& Siemer, 2004). Efforts to better understand this aspect of our mental landscape are therefore not trivial.

Given the salience of emotion regulatory processes in psychological health, it has become a major field of research in recent years (Gross, 2014). Naturally, many measures seeking to measure individual differences in emotion regulation have been developed in the process. Examples include the Emotion Control Questionnaire (ECQ) (Roger \& Nesshoever, 1987), the Emotion Regulation Questionnaire (ERQ) (Gross \& John, 2003), Difficulties in Emotion Regulation Scale (DERS) (Gratz \& Roemer, 2004), Regulation of Emotions Questionnaire (REQ) (Phillips \& Power, 2007), Affective Style Questionnaire (ASQ) (Hofmann \& Kashdan, 2010), the Emotion Regulation Profile-Revised (ERP-R) (Nelis, Quoidbach, Hansenne, \& Mikolajczak, 2011), the Emotion Regulation of Others and Self (EROS) (Niven, Totterdell, Stride, \& Holman, 2011) and the State Difficulties in Emotion Regulation Scale (S-DERS) (Lavender, Tull, DiLillo, Messman-Moore, \& Gratz, 2015). 
While this list is not exhaustive, it showcases a variety of measures that have been developed in an effort to investigate the antecedents and consequences of emotion regulation, or components thereof (John \& Eng, 2014). Importantly, John and Eng (2014) differentiated among three individual difference approaches to the measurement of emotion regulation. The first approach represents measures based on Gross's (1998) process model, the second on coping with stressors and the third is focused on emotional competences. The focus of the present study is on the Cognitive Emotion Regulation Questionnaire-short (CERQ-short). The CERQ is considered a measure of the second type, as its focus is on coping, or managing emotions in regards to stressors over a longer term (Garnefski, Kraaij, \& Spinhoven, 2001; John \& Eng, 2014). This approach is differentiated from the other two approaches, as it does not focus on changing immediate behavioural-expressive components of affect (approach 1), and is not focused on emotional competences aimed at appropriate socio-emotional behaviour (approach 3; John \& Eng, 2014).

Garnefski et al.'s (2001) model for the CERQ categorises cognitive emotion regulation into nine different strategies, namely Self-Blame, Other-Blame, Positive Reappraisal, Rumination, Catastrophising, Putting-into-Perspective, Positive Refocusing, Acceptance and Refocus on Planning (Garnefski et al., 2001). These cognitive emotion regulation strategies have all been linked to the presence or absence of psychopathology. While some strategies are adaptive (Putting-into-Perspective, Positive Refocusing, Positive Reappraisal, Acceptance and Refocus on Planning), others are considered maladaptive (Self-Blame, Blaming Others, Rumination and Catastrophising), and are associated with psychological distress and psychopathology (Aldao, 2012; Garnefski et al., 2002; Garnefksi \& Kraaij, 2007; Jermann, Van der Linden, d'Acremont, \& Zermatten, 2006; Martin \& Dahlen, 2005). In contrast, the adaptive strategies have been positively associated with higher levels of optimism and self-confidence and correlated negatively with several psychopathologies (Garnefski et al., 2002).

The original CERQ (Garnefski et al., 2001) contains 36 items, although a shorter 18 -item version was created some years later (Garnefski \& Kraaij, 2006), with two items per subscale instead of four. The CERQ-short is the focus of the present study. For the original version, support for construct validity came from a principal components analysis with nine factors extracted, consistent with the hypothesised model (Garnefski \& Kraaij, 2007; Garnefski et al., 2001). Principal components analysis was similarly performed on the shortened version (Garnefski \& Kraaij, 2006) to again assess construct validity. Confusingly, the authors used oblimin and varimax rotations inconsistently across these studies with no clear rationale provided for either option, although one would theoretically expect the factors to be somewhat correlated. Cronbach's alpha reliability ranged between 0.75 and 0.87 for the four-item version and between 0.68 and 0.81 for the short version (Garnefski \& Kraaij, 2006). Slightly weaker alpha reliabilities were reported in an earlier study for the full version (Garnefski et al., 2001).

\section{Objectives of the study}

The objective of the present article is to investigate the psychometric properties of the CERQ-short in South Africa. There is a dearth of validation research on measures of cognitive emotion regulation in South Africa. In fact, a search of the literature found no such research conducted in this context. While previous findings seemed promising in its country of origin, the extent to which the CERQ-short functions adequately in South Africa needs to be examined, given the extreme diversity of the population. As such, the psychometric properties of the CERQ-short are investigated in this article, with specific focus on the reliability and factor structure (Garnefski \& Kraaij, 2006) of the measure.

\section{Method \\ Participants}

The study population comprised 1904 undergraduate students $($ mean $=20$ years, standard deviation $[\mathrm{SD}]=2.5$ years) studying psychology at a large urban university in the Gauteng province of South Africa, who were invited to participate voluntarily. The data were not stratified in any other way. Most of the participants were women ( $n=1447$, $76 \%)$. From an ethnic perspective, the majority were black participants $(76 \%, n=1446)$, followed by white participants $(11.7 \%, n=222)$. Home language representation were as follows: Afrikaans (4.5\%), English (22.7\%), isiNdebele (11.3\%), isiXhosa (5.8\%), isiZulu (19.8\%), Sepedi (11.9\%), Sesotho (7.9\%), Setswana (10.5\%), Siswati $(5 \%)$, Tshivenda (3.3\%), Xitsonga (6.5\%) and unspecified (0.8\%).

\section{Instruments}

The CERQ-short (Garnefski \& Kraaij, 2006) is an 18-item scale used to measure an individual's cognitive emotion regulation strategies in relation to negative or unpleasant events that are experienced. Participants have to indicate how they respond and what they think about when they experience such an event. For example, items on the Acceptance scale include 'I think that I have to accept that this has happened' and 'I think that I have to accept the situation'. Participants respond to questions on a five-point Likert scale from 1 = almost never to 5 = almost always. The 18 items on the scale are divided into nine different subscales with each scale consisting of two items. The individual scale scores are calculated by adding the scores belonging to each subscale (ranging from 2 to 10). The higher the score on a subscale, the more it is used as a specific cognitive strategy. In comparison to the original CERQ, the CERQ-short demonstrated suitable reliability, with alpha scores ranging from 0.68 to 0.81 , and principal components analysis has found support for the separation of items into the same original scales (Garnefski \& Kraaij, 2006). 


\section{Data analysis}

\section{Reliability analysis}

Given the Likert-type responses of the CERQ-short, reliability estimates were computed from a polychoric correlation matrix. Previous research has shown that Pearson correlations tend to underestimate relationships among ordered categorical variables and recommend using polychoric correlations for more precise reliability estimation (Gadermann, Guhn, \& Zumbo, 2012; Zumbo, Gadermann, \& Zeisser, 2007). Cronbach's alpha and Revelle's beta coefficients were computed. The latter can be considered an estimate akin to the worse possible split-half reliability, and also provides an indication of the amount of general factor variance in a test (Revelle \& Condon, 2018).

\section{Confirmatory factor analysis}

We investigated the internal construct validity of the measure with confirmatory factor analysis (CFA). Two models were tested, a nine-factor model, based on the theoretical model (Garnefski \& Kraaij, 2006), and a ninefactor higher order model. A nine-factor model would suggest that cognitive emotion regulation is best considered a multidimensional construct, whereas a nine-factor higher order model would support the view that the subscales of the CERQ-short are in fact components of a single unidimensional variable. To evaluate the models, we considered several goodness-of-fit indices, including the Comparative Fit Index (CFI) (Bentler, 1990), the TuckerLewis Index (TLI) (Tucker \& Lewis, 1973), Root Mean Square Error of Approximation (RMSEA) (Steiger \& Lind, 1980) and the Standardised Root Mean Square Residual. Satisfactory (SRMR) fit is typically reflected by CFI and TLI values $>0.95$ and $<0.08$ for RMSEA and SRMR (Hu \& Bentler, 1999). We made use of weighted least squares mean and variance corrected estimation (WLSMV) given its superior performance on ordered categorical responses over maximum likelihood (ML) estimation (Beauducel \& Herzberg, 2006).

\section{Procedure}

The data analysed were collected previously as part of a large project investigating wellness in an urban African context.
Permission for data collection was granted by the ethics committee of the Department of Psychology and Faculty of Humanities at a large urban university in South Africa. Participants were informed about the nature of the study and provided informed consent, acknowledging that they could withdraw from the study at any point should they wish to do so, that all information will be kept confidential and that no identifying information will be made available. The participants received the information via email, along with a link that took them to the questionnaire containing demographic questions and the psychological measures. The results were only used for research purposes.

\section{Ethical considerations}

Permission for data collection was granted by the ethics committee of the Department of Psychology, and the Faculty of Humanities at a large urban university in South Africa (Ethical clearance number: REC01-056-2016).

\section{Results}

Descriptive statistics and zero-order correlations among the subscales are reported in Table 1 . Statistically significant correlations ranged between 0.08 (Self-Blame and Positive Reappraisal) and 0.51 (Refocus on Planning and Positive Reappraisal). It is worth noting that while there is variation with regard to the intercorrelations of this study compared to Garnefski and Kraai's (2006) findings, the pattern is quite similar. Strong and weak associations were consistently observed among the same variables in both studies. For example, while the previous correlation observed between Acceptance and Positive Reappraisal was 0.43 , it is 0.46 in the present study, and whereas Catastrophising and Refocus on Planning previously correlated 0.09 , they correlated 0.11 in the present study.

\section{Reliability analysis}

Inspection of the results in Table 2 shows acceptable to good reliability for most scales (Kline, 2011), with the exception of Rumination, Refocusing on Planning and Putting-intoPerspective, for which reliability was weaker than expected. The similarity in results across alpha and beta is likely because of the small number of items per scale (two).

TABLE 1: Zero-order intercorrelations and descriptive statistics for the scales of the Cognitive Emotion Regulation Questionnaire-short.

\begin{tabular}{|c|c|c|c|c|c|c|c|c|c|}
\hline Scale & 1 & 2 & 3 & 4 & 5 & 6 & 7 & 8 & 9 \\
\hline 1. Acceptance & - & - & - & - & - & - & - & - & - \\
\hline 2. Rumination & $0.237 * *$ & - & - & - & - & - & - & - & - \\
\hline 3. Reappraisal & $0.455^{* *}$ & $0.224 * *$ & - & - & - & - & - & - & - \\
\hline 4. Self-Blame & $0.141 * *$ & $0.337 * *$ & $0.077 * *$ & - & - & - & - & - & - \\
\hline 5. Refocusing & $0.259 * *$ & $0.097 * *$ & $0.322 * *$ & $0.123^{* *}$ & - & - & - & - & - \\
\hline 6. Catastrophise & 0.033 & $0.462 * *$ & 0.009 & $0.334 * *$ & -0.004 & - & - & - & - \\
\hline 7. Other-Blame & 0.012 & $0.173 * *$ & 0.009 & $0.129 * *$ & $0.222 * *$ & $0.375 * *$ & - & - & - \\
\hline 8. Planning & $0.299 * *$ & $0.222^{* *}$ & $0.505 * *$ & $0.224 * *$ & $0.317 * *$ & $0.104 * *$ & $0.101 * *$ & - & - \\
\hline 9. Perspective & $0.303^{* *}$ & $0.095^{* *}$ & $0.359 * *$ & $0.160 * *$ & $0.373 * *$ & -0.017 & $0.134 * *$ & $0.422 * *$ & - \\
\hline Mean & 7.030 & 6.610 & 7.810 & 5.250 & 5.400 & 5.300 & 3.970 & 7.090 & 6.250 \\
\hline Standard deviation & 2.090 & 1.890 & 1.940 & 2.170 & 2.040 & 2.230 & 1.890 & 2.050 & 2.130 \\
\hline
\end{tabular}

Note: 3 , positive reappraisal; 5 , positive refocusing; 6 , catastrophising; 8 , refocus on planning; 9 , putting-into-perspective.

$* *, p<0.01$ 
TABLE 2: Reliability estimates for the Cognitive Emotion Regulation Questionnaireshort scales.

\begin{tabular}{lccccc}
\hline Variable & \multicolumn{2}{c}{$\begin{array}{c}\text { Polychoric-based } \\
\text { correlations } \dagger^{\dagger}\end{array}$} & & \multicolumn{2}{c}{$\begin{array}{c}\text { Pearson-based } \\
\text { correlations: }\end{array}$} \\
\cline { 2 - 3 } \cline { 5 - 6 } & $\boldsymbol{\alpha}$ & $\boldsymbol{\beta}$ & & $\boldsymbol{\alpha}$ & $\boldsymbol{\beta}$ \\
\hline 1. Acceptance & 0.76 & 0.76 & & 0.71 & 0.71 \\
2. Rumination & 0.58 & 0.58 & & 0.53 & 0.53 \\
3. Reappraisal & 0.73 & 0.73 & & 0.67 & 0.67 \\
4. Self-Blame & 0.71 & 0.71 & & 0.66 & 0.66 \\
5. Refocusing & 0.65 & 0.65 & & 0.61 & 0.61 \\
6. Catastrophise & 0.81 & 0.81 & & 0.77 & 0.77 \\
7. Other-Blame & 0.81 & 0.81 & & 0.75 & 0.75 \\
8. Planning & 0.71 & 0.71 & & 0.67 & 0.67 \\
9. Perspective & 0.64 & 0.64 & & 0.60 & 0.60 \\
\hline
\end{tabular}

Note: 3 , positive reappraisal; 5 , positive refocusing; 6 , catastrophising; 8 , refocus on planning; 9 , putting-into-perspective; $\alpha$, Cronbach's alpha; $\beta$, Revelle's beta.

$\dagger$, Polychoric correlation-based reliability estimates.

\pm Pearson correlation-based reliability estimates.

TABLE 3: Goodness-of-fit statistics for the nine-factor and nine-factor highe order models.

\begin{tabular}{lcccccc}
\hline Model & $\chi^{2}$ (df) & CFI & TLI & \multicolumn{2}{c}{ RMSEA } & SRMR \\
\cline { 3 - 6 } & & & & $\begin{array}{c}\text { Point } \\
\text { estimate }\end{array}$ & $\begin{array}{c}\mathbf{9 0 \%} \\
\text { Cl }\end{array}$ & \\
\hline $\begin{array}{l}\text { Nine-factor model } \\
\text { Nine-factor higher }\end{array}$ & $1031.9(99)$ & 0.94 & 0.91 & 0.07 & {$[0.067-074]$} & 0.045 \\
$\begin{array}{l}\text { order model } \\
\text { 4126) }\end{array}$ & 0.75 & 0.70 & 0.13 & {$[0.126-133]$} & 0.109 \\
\hline
\end{tabular}

CFI, Comparative Fit Index; TLI, Tucker-Lewis Index; RMESA, root mean square error of approximation; SRMR, standardised root mean square residual: $\mathrm{Cl}$, confidence interval; $\mathrm{df}$, degrees of freedom.

For comparison, Pearson correlation-based estimates of Cronbach's alpha and Revelle's beta are also reported in the table, which are lower across the board, compared to the polychoric-based estimates.

\section{Confirmatory factor analysis}

Results for the two confirmatory factor analytic models that were tested are reported in Table 3 . We found reasonable support for the nine-factor model only. The nine-factor higher order model was not supported as evidenced by the weak goodness-of-fit values. As such, we proceeded to examine the factor loadings of the basic nine-factor model, as reported in Table 4 .

All items were statistically significant and had good standardised loadings on their expected factors, ranging between 0.601 and 0.867 (Tabachnick \& Fidell, 2007). Inspection of the correlated residuals revealed five larger than 0.10 (Kline, 2011). However, in each case there was no apparent content overlap on the item pairs to justify making modifications to the model. Overall, the results suggest that the sub-facets of the CERQ are well defined by their items.

\section{Discussion}

The purpose of this study was to examine the reliability and internal factor structure of the CERQ-short. While previous research has found fairly good support for the reliability and construct validity of the CERQ-full and short versions in a different population (Garnefski \& Kraaij, 2006, 2007; Garnefski et al., 2001), no studies have been conducted to examine its utility in the South African context. This article sought to do this for the CERQ-short.
TABLE 4: Standardised and unstandardised coefficients for the items of the Cognitive Emotion Regulation Questionnaire-short.

\begin{tabular}{llccc}
\hline Item & Latent construct & $\boldsymbol{\beta}$ & $\boldsymbol{B}$ & Standard error \\
\hline I1 & Acceptance & 0.758 & 1.000 & - \\
I5 & Acceptance & 0.802 & 1.058 & 0.042 \\
I2 & Rumination & 0.601 & 1.000 & - \\
I6 & Rumination & 0.677 & 1.126 & 0.047 \\
I3 & Positive Reappraisal & 0.752 & 1.000 & - \\
I8 & Positive Reappraisal & 0.762 & 1.013 & 0.031 \\
I4 & Self-Blame & 0.706 & 1.000 & - \\
I14 & Self-Blame & 0.785 & 1.111 & 0.054 \\
I7 & Positive Refocusing & 0.630 & 1.000 & - \\
I11 & Positive Refocusing & 0.761 & 1.207 & 0.061 \\
I9 & Catastrophising & 0.789 & 1.000 & - \\
I17 & Catastrophising & 0.867 & 1.100 & 0.031 \\
I10 & Other-Blame & 0.840 & 1.000 & - \\
I18 & Other-Blame & 0.820 & 0.977 & 0.046 \\
I12 & Refocus on Planning & 0.682 & 1.000 & - \\
I15 & Refocus on Planning & 0.814 & 1.193 & 0.039 \\
I13 & Putting-into-Perspective & 0.680 & 1.000 & - \\
I16 & Putting-into-Perspective & 0.687 & 1.011 & 0.043 \\
\hline
\end{tabular}

In terms of reliability, most scales yielded acceptable to good reliability; however, Rumination $(\alpha=0.58)$, Refocusing on Planning ( $\alpha=0.65)$ and Putting-into-Perspective $(\alpha=$ $0.64)$ had reliability coefficients that were weaker than expected. This is substantially lower than what was previously found by Garnefski and Kraaij (2006), who reported an alpha coefficient of 0.79 for Rumination, Positive Refocusing and Putting-into-Perspective. The remaining scales had acceptable reliabilities, ranging between 0.71 and 0.81 , which are consistent with previous findings (Garnefski \& Kraaij, 2006).

Regarding the factor structure of the CERQ-short, results of the basic nine-factor model provided reasonable support for the separation of items into nine different scales. However, a nine-factor higher order model did not provide adequate fit for the data, and suggests that cognitive emotion regulation as measured by the CERQ-short is best considered a multidimensional rather than a unidimensional construct. This is reflected by the weak goodness-of-fit values observed for the nine-factor higher order model which does not support the idea that cognitive emotion regulation can be considered a unidimensional latent construct. However, the present data suggest that it can be indexed using a multidimensional approach as represented by the nine-factor model. This model supports the CERQ-short as a measure comprising meaningful constructs, with all items having strong loadings on their respective factors.

Importantly, this study examined the CERQ-short using CFA. Previous research mostly used principal components analysis, with one exception in Garnefski and Kraaij (2007), whose findings were insufficiently reported. Principal components analysis represents formative modelling, whereas CFA comprises reflective modelling (Fleuren, Van Amelsvoort, Zijlstra, De Grip, \& Kant, 2018; Howell, Breivik, \& Wilcox, 2007; Jarvis, MacKenzie, \& Podsakoff, 2003). The use of principal components analysis rather than 
CFA, arguably, represents theoretical misspecification. A clear a priori theoretical structure (Garnefski \& Kraaij, 2006; Garnefski et al., 2001) along with a consideration of typical criteria for reflective modelling (Fleuren et al., 2018) suggested that CFA was a more appropriate method with which to investigate the factor structure of the CERQ-short.

Although previous research conducted in a different country reported satisfactory measurement properties for the CERQ-short (Garnefski \& Kraaij, 2006), its functioning in South Africa was found to be slightly weaker in general. While the reliability for six out of nine scales was acceptable, reliability for the three remaining scales was not satisfactory - especially problematic was the Rumination scale. It is possible that a latent variable estimate of reliability, such as McDonald's (1999) omega, could perhaps paint a different picture than the Cronbach's alpha coefficients; however, with two items per scale, it was not possible to compute.

This study has some limitations that should be considered when interpreting the results. The data collected were from an urban student population in one part of South Africa. English was not the first language of all participants, which may have impacted how questions were understood and interpreted. The sample consisted of university students who may not represent the general South African population and thus may limit the generalisability of the results.

While this study focused on the CERQ-short, future research using similar analyses is required on the full version of the measure. As such, the findings of this study should not be extrapolated to the full version. Future research should also explore if the measure functions equivalently across different gender, ethnic and language groups. This would subsequently allow investigation of group differences in cognitive emotion regulation.

\section{Conclusion}

Considered together, the results of this study showed reasonable support for the reliability and construct validity of the CERQ-short, with noted exceptions. It should be borne in mind that these findings likely represent a best-case scenario given the use of polychoric correlations. In comparison to the polychoric-based results, the Pearsonbased reliability estimates reported in Table 2 were much less promising. The goodness-of-fit statistics, in particular the incremental fit indices (CFI and TLI), are also not above reproach. Nevertheless, the CERQ-short offers some promise for use in the South African context. Without data on the full version, one can only speculate about how it might function in South Africa. From previous work conducted elsewhere, it seems likely that the full version would provide more stable measurement than the short version. However, in the absence of empirical data, this remains a conjecture, and the short version is recommended for use in South Africa until research that supports the full version is produced.

\section{Acknowledgments Competing interests}

The authors declare that they have no financial or personal relationships that may have inappropriately influenced them in writing this article.

\section{Authors' contributions}

Both I.P. and C.J.J.v.Z. worked on the entire manuscript. I.P. focused on the literature review and discussion and C.J.J.v.Z. focused on the method and results.

\section{Funding}

This research received no specific grant from any funding agency in the public, commercial or not-for-profit sectors.

\section{Disclaimer}

The views expressed in this article are the authors' own and are not the official position of their institution.

\section{Data availability statement}

The data for this study is not publicly available.

\section{References}

Aldao, A. (2012). Emotion regulation strategies as transdiagnostic processes: A closer look at the invariance of their form and function. Spanish Journal of Clinical Psychology, 17(3), 261-277. Retrieved from http://e-spacio.uned.es/fez/eserv/bi bliuned:Psicopat-2012-17-3-6025/Documento.pdf

Beauducel, A., \& Herzberg, P.Y. (2006). On the performance of maximum likelihood versus means and variance adjusted weighted least squares estimation in CFA. Structural Equation Modeling, 13(2), 186-203. https://doi.org/10.1207/ s15328007sem1302_2

Bebko, G.M., Ochsner, K.N., Franconeri, S.L., \& Chiao, J.Y. (2014). Attentional deployment is not necessary for successful emotion regulation via cognitive reappraisal or expressive suppression. Emotion, 14(3), 504-512. https://doi.org/10.1037/a0035459

Bentler, P.M. (1990). Comparative fit indexes in structural models. Psychological Bulletin, 107(2), 238-246. https://doi.org/10.1037/0033-2909.107.2.238

Davidson, R.J. (1998). Affective style and affective disorders: Perspectives from affective neuroscience. Cognition and Emotion, 12(3), 307-330. https://doi.org/ 10.1080/026999398379628

Fleuren, B.P.I., Van Amelsvoort, L.G.P.M., Zijlstra, F.R.H., De Grip, A., \& Kant, I. (2018) Handling the reflective-formative measurement conundrum: A practical illustration based on sustainable employability. Journal of Clinical Epidemiology, 103, 71-81. https://doi.org/10.1016/j.jclinepi.2018.07.007

Fitzpatrick, S., Khoury, J.E., \& Kuo, J.R. (2018). Examining the relationship between emotion regulation deficits and borderline personality disorder features: A daily diary study. Counselling Psychology Quarterly, 31, 42-58. https://doi.org/10.1080 diary study. Counselling Psy

Gadermann, A.M., Guhn, M., \& Zumbo, B.D. (2012). Estimating ordinal reliability for Likert-type and ordinal item response data: A conceptual, empirical, and practical guide. Practical Assessment, Research \& Evaluation, 17(3). Retrieved from https:// www.pareonline.net/getvn.asp?v $=17 \& n=3$

Garnefski, N., \& Kraaij, V. (2006). Cognitive emotion regulation questionnaire Development of a short 18-item version (CERQ-short). Personality and Individual Differences, 41, 1045-1053. https://doi.org/10.1016/j.paid.2006.04.010

Garnefski, N., \& Kraaij, V. (2007). The cognitive emotion regulation questionnaire: Pscyhometric features and prospective relationships with depression and anxiety in adults. European Journal of Psychological Assessment, 23(3), 141-149. https:// doi.org/10.1027/1015-5759.23.3.141

Garnefski, N., Kraaij, V., \& Spinhoven, P. (2001). Negative life events, cognitive emotion regulation and emotional problems. Personality and Individual Differences, 30 , 1311-1327. https://doi.org/10.1016/S0191-8869(00)00113-6

Garnefski, N., Van den Kommer, T., Kraaij, V., Teerds, J., Legerstee, J., \& Onstein, E. (2002). The relationship between cognitive emotion regulation strategies and emotional problems. European Journal of Personality, 16, 403-420.

Gratz, K.L., \& Roemer, L. (2004). Multidimensional assessment of emotion regulation and dysregulation: Development, factor structure, and initial validation of the difficulties in emotion regulation scale. Journal of Psychopathology and Behavioral Assessment, 26(1), 41-54. https://doi.org/10.1023/B:JOBA.0000007455.08539.94 
Gross, J.J. (1998). The emerging field of emotion regulation: An integrative review. Review of General Psychology, 2(3), 271-299. https://doi.org/10.1037/1089Review of Gene
2680.2.3.271

Gross, J.J. (2014). Emotion regulation: Conceptual and empirical foundations. In J.J. Gross (Ed.), Handbook of emotion regulation (2nd edn., pp. 3-10). New York: Guilford Press.

Gross, J.J., \& Jazaieri, H. (2014). Emotion, emotion regulation, and psychopathology: An affective science perspective. Clinical Psychological Science, 2(4), 387-401. https://doi.org/10.1177/2167702614536164

Gross, J.J., \& John, O.P. (2003). Individual differences in two emotion regulation processes: Implications for affect, relationships, and well-being. Journal of Personality and Social Psychology, 85(2), 348-362. https://doi.org/10.1037/0022 3514.85.2.348

Gruber, J., Hay, A.C., \& Gross, J.J. (2014). Rethinking emotion: Cognitive reappraisal is an effective positive and negative emotion regulation strategy in bipolar disorder Emotion, 14(2), 388-396. https://doi.org/10.1037/a0035249

Hofmann, S.G., \& Kashdan, T.B. (2010). The affective style questionnaire: Development and psychometric properties. Journal of Psychopathology and Behavioral Assessment, 32, 255-263. https://doi.org/10.1007/s10862-009-9142-4

Howell, R.D., Breivik, E., \& Wilcox, J.B. (2007). Reconsidering formative measurement Psychological Methods, 12, 205-218. https://doi.org/10.1037/1082-989X.12.2.205

$\mathrm{Hu}$, L., \& Bentler, P.M. (1999). Cutoff criteria for fit indexes in covariance structure analysis: Conventional criteria versus new alternatives. Structural Equation Modeling, 6(1), 1-55. https://doi.org/10.1080/10705519909540118

Jarvis, C.B., MacKenzie, S.B., \& Podsakoff, P.M. (2003). A critical review of construct indicators and measurement model misspecification in marketing and consume research. Journal of Consumer Research, 30, 199-218. https://doi.org/10.1086/ 376806

Jermann, F., Van der Linder, M., d'Acremont, M., \& Zermatten, A. (2006). Cognitive emotion regulation questionnaire (CERQ) confirmatory factor analysis and psychometric properties of the French translation. European Journal of Psychological Assessment, 22(2), 126-131. https://doi.org/10.1027/1015-5759.22.2.126

John, O.P., \& Eng, J. (2014). Three approaches to individual differences in affect regulation: Conceptualizations, measures and findings. In J.J. Gross (Ed.), Handbook of emotion regulation (2nd edn., pp. 321-345). New York: The Guildford Press.

Joormann, J., \& Siemer, M. (2004). Memory accessibility, mood regulation, and dysphoria: Difficulties in repairing sad mood with happy memories? Journal of Abnormal Psychology, 113(2), 179-188. https://doi.org/10.1037/0021-843X.113.2.179

Klemanski, D.H., Curtiss, J., McLaughlin, K.A., \& Nolen-Hoeksema, S. (2017). Emotion regulation and the transdiagnostic role of repetitive negative thinking in adolescents with social anxiety and depression. Cognitive Therapy Research, 41, 206-219. https://doi.org/10.1007/s10608-016-9817-6
Kline, R.B. (2011). Principles and practice of structural equation modelling (2nd edn.). New York: Guildford Press.

Koole, S.L. (2009). The psychology of emotion regulation: An integrative review. Cognition and Emotion, 23(1), 4-41. https://doi.org/10.1080/02699930802619031

Lavender, J.M., Tull, M.T., DiLillo, D., Messman-Moore, T., \& Gratz, K.L. (2015). Development and validation of a state-based measure of emotion dysregulation: The state difficulties in emotion regulation scale (S-DERS). Assessment, 24(2), 197-209. https://doi.org/10.1177/1073191115601218

Mallorqui-Bague, N., Vintro-Alcaraz, C., Sanchez, I., Riesco, N., Aguera, Z., Granero, R., ... Fernandez-Aranda, F. (2017). Emotion regulation as a transdiagnostic feature among eating disorders: Cross-sectional and longitudinal approach. European Eating Disorders Review, 26(1), 53-61. https://doi.org/10.1002/erv.2570

Martin, R.C., \& Dahlen, E.R. (2005). Cognitive emotion regulation in the prediction of depression, anxiety, stress, and anger. Personality and Individual Differences, 39 1249-1260. https://doi.org/10.1016/j.paid.2005.06.004

McDonald, R.P. (1999). Test theory: A unified treatment. Mahwah, NJ: Lawrence Erlbaum Associates.

Nelis, D., Quoidbach, J., Hansenne, M., \& Mikolajczk, M. (2011). Measuring individual differences in emotion regulation: The emotion regulation profile-revised (ERP-R). Psychologica Belgica, 51(1), 49-91. https://doi.org/10.5334/pb-51-1-49

Niven, K., Totterdell, P., Stride, C.B., \& Holman, D. (2011). Emotion regulation of others and self (EROS): The development and validation of a new individual difference measure. Current Psychology, 30(1), 53-73. https://doi.org/10.1007/s12144-0119099-9

Phillips, K.F.V., \& Power, M.J. (2007). A new self-report measure of emotion regulation in adolescents: The regulation of emotions questionnaire. Clinical Psychology and Psychotherapy, 14, 145-156. https://doi.org/10.1002/cpp.523

Revelle, W., \& Condon, D.M. (2018, June 10). Reliability from alpha to omega: A tutorial. https://doi.org/10.31234/osf.io/2y3w9

Roger, D., \& Nesshoever, W. (1987). The construction and preliminary validation of a scale for measuring emotional control. Personality and Individual Differences, 8(4), 527-534. https://doi.org/10.1016/0191-8869(87)90215-7

Steiger, J.H., \& Lind, J.M. (1980). Statistically based tests for the number of factors. Paper presented at the Annual Meeting of the Psychometric Society, lowa City, IA.

Tabachnick, B.G., \& Fidell, L.S. (2007). Using multivariate statistics. Boston, MA: Allyn \& Bacon/Pearson Education.

Tucker, L.R., \& Lewis, C. (1973). A reliability coefficient for maximum likelihood factor analysis. Psychometrika, 38(1), 1-10. https://doi.org/10.1007/BF02291170

Zumbo, B.D., Gadermann, A.M., \& Zeisser, C. (2007). Ordinal versions of coefficients alpha and theta for Likert rating scales. Journal of Modern Applied Statistical Methods, 6(1), 21-29. https://doi.org/10.22237/jmasm/1177992180 